University of Nebraska - Lincoln

DigitalCommons@University of Nebraska - Lincoln

Uniformed Services University of the Health

Sciences

U.S. Department of Defense

2008

Evaluation and management of peripheral nerve injury

William W. Campbell

Uniformed Services University of Health Sciences, wcampbell@usuhs.edu

Follow this and additional works at: https://digitalcommons.unl.edu/usuhs

Part of the Medicine and Health Sciences Commons

Campbell, William W., "Evaluation and management of peripheral nerve injury" (2008). Uniformed Services University of the Health Sciences. 3.

https://digitalcommons.unl.edu/usuhs/3

This Article is brought to you for free and open access by the U.S. Department of Defense at DigitalCommons@University of Nebraska - Lincoln. It has been accepted for inclusion in Uniformed Services University of the Health Sciences by an authorized administrator of DigitalCommons@University of Nebraska Lincoln. 


\title{
Evaluation and management of peripheral nerve injury is
}

\author{
William W. Campbell* \\ Department of Neurology, Uniformed Services University of Health Sciences, Room A 1036, 4301 Jones Bridge Road, Bethesda, MD 20814, USA
}

Accepted 7 March 2008

Available online 14 May 2008

\begin{abstract}
Common etiologies of acute traumatic peripheral nerve injury (TPNI) include penetrating injury, crush, stretch, and ischemia. Management of TPNI requires familiarity with the relevant anatomy, pathology, pathophysiology, and the surgical principles, approaches and concerns. Surgical repair of TPNI is done at varying time intervals after the injury, and there are a number of considerations in deciding whether and when to operate. In neurapraxia, the compound muscle and nerve action potentials on stimulating distal to the lesion are maintained indefinitely; stimulation above the lesion reveals partial or complete conduction block. The picture in axonotmesis and neurotmesis depends on the time since injury. The optimal timing for an electrodiagnostic study depends upon the clinical question being asked. Although conventional teaching usually holds that an electrodiagnostic study should not be done until about 3 weeks after the injury, in fact a great deal of important information can be obtained by studies done in the first week. Proximal nerve injuries are problematic because the long distance makes it difficult to reinnervate distal muscles before irreversible changes occur. Decision making regarding exploration must occur more quickly, and exploration using intraoperative nerve action potential recording to guide the choice of surgical procedure is often useful.
\end{abstract}

Published by Elsevier Ireland Ltd on behalf of International Federation of Clinical Neurophysiology.

Keywords: Trauma; Injury; Peripheral nerve; Electrodiagnosis; Electromyography; Surgery

\section{Introduction}

Etiologies of traumatic peripheral nerve injury (TPNI) include penetrating injury, crush, traction, ischemia, and less common mechanisms such as thermal, electric shock, radiation, percussion, and vibration (Robinson, 2000, 2004). In general, stretch-related injuries are the most common type of civilian nerve trauma, especially in motor vehicle accidents. Lacerations, as by glass, knife, fan, saw blade, auto metal or long bone fractures make up about $30 \%$ of serious nerve injuries. Another common injury mechanism is compression, which may involve mechanical deformation as well as ischemia (Stanec et al., 1997). Kouyoumdjian reported a 16-year retrospective study of

\footnotetext{
The opinions or assertions contained herein are the private views of the author and are not to be construed as official or as reflecting the views of the Department of the Army or the Department of Defense.

${ }^{*}$ Tel.: +1 301295 3643; fax: +1 3012950620.

E-mail addresses: wcampbell@usuhs.mil,wcampbell@usuhs.edu
}

456 consecutive patients with 557 peripheral nerve injuries (Kouyoumdjian, 2006). Upper-limb injuries occurred in $73.5 \%$ of cases; the ulnar nerve was most often injured, either singly or in combination. Combined lesions most commonly involved the ulnar and median nerves. Motor vehicle accidents, particularly motorcycle crashes, were the most common cause of injury (Stanec et al., 1997). In a series of 1167 cases of peripheral nerve injury, $5.7 \%$ of cases were related to sports (Hirasawa and Sakakida, 1983).

Peripheral nerve injuries were first studied systematically during the American Civil War by neurologist S. Weir Mitchell. Many of the advances in knowledge about peripheral nerve injuries have occurred during wartime, from physicians on both sides of the front. In a military setting, most peripheral nerve injuries are due to shrapnel (Maricevic and Erceg, 1997). A common cause of TPNI in combat is blast injury, often from bombs or improvised explosive devices. Blast typically causes a complex, extensive, soft-tissue injury, frequently with vascular injuries 
requiring emergency arterial repair. The arterial injury may produce limb ischemia requiring fasciotomy. Peripheral nerves may be involved because of the concussive force of blast overpressure, shrapnel, or limb ischemia with compartment syndrome. In a series of 151 upper limb war injuries seen in Croatia, about one-third of the nerve injuries had associated arterial injuries. Functional results were obtained in only $44.8 \%$ of cases with both nerve and arterial injuries, an outcome likely due in part to nerve ischemia at the injury site (Stanec et al., 1997; Selecki et al., 1982).

In the current Middle East conflict, the protection afforded to coalition soldiers by body armor has resulted in a markedly increased incidence of peripheral nerve injuries, as combatants survive wounds that would formerly have been lethal. The wounded in action to killed in action ratio among coalition forces in the current conflict is about 8:1, compared to 3:1 in past conflicts, even as recently as Vietnam. The result has been a marked increase in extremely grievous extremity wounds, with many amputations and many TPNIs. Recently developed extremity body armor will hopefully lessen the incidence of the major extremity wounds. The lightweight, flexible extremity body armor is designed to protect the vulnerable areas near major nerves and blood vessels. Non-battle related peripheral nerve syndromes are also common in a combat environment (Hartmann, 2006).

This review will emphasize the clinical and electrodiagnostic aspects of the care of patients with TPNI.

\section{Neuropathology of peripheral nerve injury}

To manage patients with TPNI, it is important to be knowledgeable about the relevant anatomy, pathology, pathophysiology, electrodiagnosis, and principles of surgical management. Understanding the anatomy is crucial to grasping the pathophysiologic concepts that underlie the clinical management of patients with peripheral nerve injuries (Burnett and Zager, 2004; Maggi et al., 2003). Because the clinical neurophysiologist works closely with the surgeon in managing these cases, it is also important to be familiar with surgical principles, approaches, and concerns.

The endoneurium surrounds individual myelinated axons and groups of unmyelinated ones. Fascicles are collections of axons which are surrounded by perineurium. The epifascicular (internal) epineurium lies between fasci- cles. The peripheral nerve trunk is a collection of fascicles, and the epineurial (external) epineurium surrounds the nerve trunk proper. The endoneurium is longitudinally oriented while the perineurium and epineurium are circumferential (Sunderland, 1990). Plexuses of microvessels run longitudinally in the epineurium, and send transverse branches through the perineurium to form a vascular network consisting primarily of capillaries in the endoneurium. Nerve trauma increases the permeability of the epineurial vessels, which are more susceptible to compression trauma than the endoneurial vessels. Higher pressure levels or more prolonged compression will also injure the endoneurial vessels, leading to intrafascicular edema, which may lead to secondary injury to the nerve (Rydevik and Lundborg, 1977).

There are two commonly used classification schemes for peripheral nerve injury: the Seddon and the Sunderland (Table 1). The Sunderland classification is more complex, but more useful. It is important for the clinical neurophysiologist to be familiar with these classification schemes because they are in widespread use in the surgical community. Seddon divided injuries into neurapraxia, axonotmesis and neurotmesis (Seddon, 1943). In neurapraxia (not neuropraxia), the nerve is intact but cannot transmit impulses (praxis $=$ to do, to perform). In axonotmesis (tmesis $=$ to cut), the axon is damaged or destroyed, but most of the connective tissue framework is maintained. In neurotmesis, the nerve trunk is disrupted and not in anatomical continuity. Most of the connective tissue framework is lost or badly distorted.

In the setting of nerve injury, neurapraxia is due to segmental demyelination, and is equivalent to Sunderland's first degree injury. It is the mildest form of nerve injury. Axons are anatomically intact but nonfunctional; the nerve cannot transmit impulses and the body part is paralyzed. There is motor and sensory loss due to demyelination, without axon disruption or Wallerian degeneration. The conduction block due to neurapraxia usually affects motor fibers more than sensory fibers. Clinically, muscle atrophy does not develop except for mild atrophy due to disuse. Electrophysiologically, the nerve conducts normally distally but there is impaired conduction across the lesion because of focal demyelination. Loss of function persists until remyelination occurs. Recovery time ranges from hours to a few months; full function can usually be expected without intervention by about 12 weeks, often

Table 1

The Seddon and Sunderland classifications of nerve injury

\begin{tabular}{lll}
\hline Seddon & Process & Sunderland \\
\hline Classification of nerve injury & Segmental demyelination & First degree \\
Neurapraxia & Axon severed but endoneurium intact (optimal circumstances for regeneration) & Second degree \\
Axonotmesis & Axon discontinuity, endoneurial tube discontinuity, perineurium and fascicular arrangement preserved & Third degree \\
Axonotmesis & Loss of continuity of axons, endoneurial tubes, perineurium and fasciculi; epineurium intact (neuroma in continuity) & Fourth degree \\
Axonotmesis & Loss of continuity of entire nerve trunk & Fifth degree \\
Neurotmesis & L &
\end{tabular}

Sunderland subdivided axonotmesis into three types with different degrees of nerve disruption and different capabilities for spontaneous regeneration. 
earlier, provided there is no ongoing compression. Motor paralysis can last as long as 6 months, but most lesions resolve by 3 months (Dumitru et al., 2001). Since axons may be remyelinated at different rates and to different degrees, function may be regained unevenly. Common examples are Saturday night radial nerve palsy and leg crossing peroneal nerve palsy. Seddon coined the term neurapraxia to refer to lesions that recovered in weeks to months (Seddon, 1943). Neurapraxia has also been used to describe rapidly reversible physiological conduction block lasting only minutes, much too transient to attribute to demyelination, as in one's foot falling asleep, presumably due to focal ischemia without any structural change in the myelin (Wilbourn, 2002). Whether ischemia can cause more prolonged conduction block, lasting days to weeks is controversial (Wilbourn, 2002).

More severe peripheral nerve injuries, such as lacerations, contusions, and injuries due to stretch, severe compression and injections, cause anatomical disruption of axons or the nerve trunk proper. Wallerian degeneration occurs when there is disruption of the axon (Koeppen, 2004; Stoll and Muller, 1999). The distal portion of the axon degenerates and fragments. Myelin is transformed into neutral fat and phagocytosed by macrophages. Debris of the axon and the myelin sheath form ovoids that are gradually digested and disappear (digestion chambers) (Chaudhry et al., 1992). Proximal to the lesion, degeneration stops at the first internode in mild injuries, but may extend further proximally in severe injuries. Within hours of injury the ends of the severed axons seal over, and the sealed ends swell with cellular organelles because anterograde axonal transport in the proximal stump and retrograde axonal transport in the distal stump persist for several days (Lunn et al., 1990). Resealing is a necessary prelude to axon regeneration from the proximal stump. The resealing process requires $\mathrm{Ca}^{++}$entry into the axoplasm and occurs rapidly (Yawo and Kuno, 1985). Potent vasoactive peptides accumulate in the axon end bulbs, which along with local mast cell degranulation and angiogenesis cause hyperemia that persists for several weeks after injury (Hall, 2005). Current evidence indicates that axonal degeneration is not a passive process, but an active programmed response to disconnection from the cell body and the target organ (Hall, 2005). Loss of the axoplasmic cytoskeleton begins within about seven days in humans, accompanied by a caspase-independent program of autodestruction (Raff et al., 2002). Axonal degeneration is dependent on a local increase in calcium concentration that activates calcium-dependent proteolytic enzymes, such as phospholipases and calpains. These compounds then effect cytoskeletal dissolution (Hall, 2005).

In the distal stump, although the axon degenerates and disappears, the connective tissue basement membranes may remain, forming endoneurial tubes. Schwann cells proliferate and line the endoneurial tubes (Schwann cell tubes, bands of Bungner). These arrays of Schwann cells and processes within the basement membrane provide the pathway and scaffolding for axonal regeneration. Wallerian degeneration begins within hours of injury and is complete by 6-8 weeks, leaving a distal stump comprising only endoneurial tubes lined by Schwann cells (Hall, 1989; Kang et al., 2003). The Schwann cells are not permanent; they involute and disappear if axonal regeneration does not occur (Hall, 1999). Experimentally, there is a progressive inability of chronically denervated Schwann cells to support axonal regeneration, but paradoxically a sustained capacity to remyelinate axons that do regenerate. Axonal interaction can effectively switch the atrophic Schwann cells back into active myelinating cells (Sulaiman and Gordon, 2000). Endoneurial tubes that do not receive a regenerating axon shrink and are eventually obliterated by scar tissue.

In axonotmesis, the axon is disrupted and Wallerian degeneration occurs. There is axon discontinuity, but the surrounding stroma is at least partially intact. Axonotmesis is commonly seen in crush and stretch injuries. Reinnervation depends upon the degree of internal disorganization, and the distance to the muscle. In neurotmesis, the nerve is completely severed or so internally disrupted that it does not regenerate spontaneously well enough to produce function. Neurotmesis is seen with sharp injury, massive trauma, or severe traction with nerve rupture. There is loss of nerve trunk continuity with complete disruption of all supporting elements; reinnervation does not occur. Without surgery, the prognosis is extremely poor. Recovery from any TPNI where there is significant axon loss and internal disruption, Sunderland third degree or worse, is apt to be prolonged and incomplete (Sunderland, 1978). The affected body part can seldom become again what it was.

\section{Nerve regeneration}

Regeneration and repair processes go on at multiple levels following nerve injury, including the nerve cell body, the segment between the neuron and the injury site (proximal stump), the injury site itself, the segment between the injury site and the end organ (distal stump), and the end organ (Burnett and Zager, 2004; Seckel, 1990). The repair process may be disrupted at one or more of these sites. With mild injuries, regeneration and repair begin almost immediately. Remyelination in neurapractic injuries can occur fairly rapidly. With more severe injuries, there is an initial shock phase, after which regeneration and repair phases continue for many months.

In the CNS, recovery of function is accomplished by plasticity, using intact areas to take over the function of damaged areas; the CNS does not repair itself. The approach of the PNS to injury is to repair itself, and this is an essential difference between the two (Burnett and Zager, 2004; Fenrich and Gordon, 2004). Repair can occur through three mechanisms: remyelination, collateral sprouting distally from preserved axons, and regeneration from the site of injury (Zochodne and Levy, 2005). Collat- 
eral sprouts can provide reinnervation in partial nerve injuries, and when there are many surviving axons they may be very effective. With lesions involving less than $20-30 \%$ of the axons, recovery is predominantly by collateral sprouting from surviving axons, and occurs over 2-6 months. When more than $90 \%$ of axons are injured, the primary mechanism of repair is regeneration from the injury site. The success of regeneration from the proximal stump depends to a large degree on the distance from the injury site. Even when good motor recovery occurs, sensory deficits, particularly in proprioception, may impair functional outcome.

Attempts at regeneration begin soon after injury (Pollock, 1995; Thomas, 1989). A cascade of events involving cell signaling molecules and neurotrophic factors occurs after nerve injury (Liuzzi and Tedeschi, 1991; Zheng and Kuffler, 2000; Zochodne and Levy, 2005). The blood-nerve barrier plays an important role (Maricevic and Erceg, 1997). Schwann cells play an indispensable role in promoting regeneration by increasing their synthesis of surface cell adhesion molecules, and by elaborating basement membrane containing extracellular matrix proteins, such as laminin and fibronectin (Fu and Gordon, 1997). Schwann cells produce neurotrophic factors that bind to tyrosine kinase receptors and are responsible for a signal that leads to gene activation (Funakoshi et al., 1993). Within $30 \mathrm{~min}$ after injury, intracellular processes that promote repair and regeneration have already been activated (Dahlin, 2006). Within days after injury, Schwann cells begin to divide and create a pool of dedifferentiated daughter cells. Without axon contact, Schwann cells downregulate their normal proteins, such as PMP22, $\mathrm{P}_{0}$ and connexin-32, and convert to the phenotype of a premyelinating cell (Hall, 2005). These dedifferentiated Schwann cells upregulate expression of nerve growth factor (NGF), other neurotrophic factors, cytokines, and other compounds that lead to Schwann cell differentiation and proliferation in anticipation of the arrival of a regenerating sprout. Nerve growth factor receptors on the Schwann cells lining the endoneurial tubes in the distal stump increase. Experimental sciatic nerve transection induces Schwann cells distal to the lesion to express greatly increased levels of NGF receptors; by 7 days the receptor density increases at least 50 -fold (Taniuchi et al., 1986). The action of NGF on these Schwann cell receptors stimulates regenerating axonal sprouts (Liuzzi and Tedeschi, 1991). After injury, macrophages migrate into the distal stump and may be involved in initiating Schwann cell proliferation. Macrophages upregulate IL-1, which induces an increase in NGF transcription and NGF receptor density, and also secrete mitogens that trigger Schwann cell proliferation (Davis and Stroobant, 1990). Neural cell surface molecules and the extracellular matrix molecules laminin and tenascin are strongly upregulated by denervated Schwann cells and may foster axonal regeneration (Martini, 1994). Cytokines play an important role. After experimental axotomy, compounds such as IL-6 and transforming growth factor-beta 1 are overexpressed in nerve and promote axonal growth until axon/Schwann cell contact (Creange et al., 1997). Inflammatory cells and their products also contribute to neuronal survival and axonal regeneration after injury. Macrophages accumulating following nerve injury supply neurotrophic support to nerve cell bodies, and enhance axonal regeneration (Richardson and $\mathrm{Lu}, 1994)$.

The stimulation effects after nerve injury radiate retrograde from the periphery to the nerve cell body, producing a stimulus that activates processes in the neuron that foster regeneration. Neuronal survival is facilitated by the activation of trophic factors from multiple sources, including neurotrophins, neuropoietic cytokines, insulinlike growth factors (IGFs), and glial-cell-line-derived neurotrophic factors (GDNFs). Axotomized neurons must switch from a transmitting mode to a growth mode and express growth-associated proteins, such as GAP-43, tubulin, and actin, as well as an array of novel neuropeptides and cytokines, all of which have the potential to promote axonal regeneration $(\mathrm{Fu}$ and Gordon, 1997). After injury there is a coordinated shift in the gene expression pattern in axotomized neurons, with a marked induction of transcription factors that occurs as early as $12 \mathrm{~h}$ after injury. Many of the upregulated genes are involved in regeneration (Dahlin, 2006). Dozens of genes are differentially expressed after experimental sciatic nerve injury using microarray analysis. Overexpression of fibroblast growth factor-inducible-14 mRNA promotes growth cone lamelipodial formation and increases neurite outgrowth in DRG cells (Tanabe et al., 2003). These alterations help shift the neuron from transmitting mode to growth mode. Endogenous neuroprotectants are also produced. Specifically, experimental sciatic nerve transection causes a 9-fold upregulation of heat shock protein 27 (HSP27) mRNA and protein in axotomized neurons in the ipsilateral DRG at $48 \mathrm{~h}$. Axotomized motor neurons also upregulate HSP27. HSP27 also appears in the axonal growth cone. HSP27 has been shown to be involved both in actin filament dynamics and in protection against necrotic and apoptotic cell death. Therefore, its upregulation after adult peripheral nerve injury may both promote survival of the injured neurons and contribute to alterations in the cytoskeleton associated with axonal growth (Costigan et al., 1998; Lewis et al., 1999). The neuron's capability to sustain regenerative attempts persists for at least 12 months after injury.

A retrograde signal from injured nerves has been found to induce interleukin-6 (IL-6) mRNA in neurons (Murphy et al., 1999; Ito et al., 1998). Interleukin-6 has been shown to be synthesized in DRG neurons after nerve transection, and in axotomized facial motor neurons. The IL-6 signal seems to be induced by an injury factor arising from the nerve stump and not by the interruption of normal retrograde transport. Mast cells may be as possible source of the factors that lead to the induction of IL-6 mRNA after nerve injury. By uncertain 
mechanisms, endogenous IL-6 seems to contribute to the survival of axotomized neurons.

Experimentally, electrical stimulation accelerates and enhances expression of regeneration-associated genes in regenerating rat femoral motoneurons (Al Majed et al., 2004). The upregulation of regeneration-associated genes occurred after $1 \mathrm{~h}$ of stimulation of divided nerves, possibly allowing more tubulin to be transported faster into the growing axons to accelerate axonal outgrowth from the proximal nerve stump. Further studies showed that one hour of electrical stimulation accelerated the functional recovery after transecting and repairing mouse femoral nerve (Ahlborn et al., 2007). Near-maximum recovery was achieved 6 weeks earlier than in the control group. This has also been found to occur with sensory neurons (Geremia et al., 2007).

The extent of the changes of central chromatolysis after nerve injury is related to the likelihood of survival of the neuron. Along with activation of gene programs that foster regeneration, there may be initiation of a cascade of caspase ("killer proteases") mediated events leading to apoptosis (Nicholson and Thornberry, 1997). The caspase family of enzymes is unique because they specifically cleave proteins next to an aspartate residue, an unusual property, and they play a key role in a biochemical cell-suicide pathway (Zhivotovsky, 2003). They mediate many of the typical biochemical and morphological changes characteristic of cells undergoing apoptosis. The extent of apoptosis of DRG cells after axotomy varies with the species and with the level of the injury, but may reach $50 \%$ in rodent models (Dahlin, 2006; Ygge, 1989). Apoptosis is more severe and rapid in sensory than motor neurons after peripheral injuries. To have a major effect on motor neurons the injury must be very proximal, as in root avulsion. In the adult mouse, root avulsion results in a type of degeneration that resembles necrosis more closely than apoptosis ( $\mathrm{Li}$ et al., 1998). Ventral root avulsion has been proposed as a model for studying mechanisms of motor neuron death and testing the ability of trophic factors and other agents to promote the survival of adult motor neurons in vivo (Koliatsos et al., 1994).

The first attempts at repair in the proximal stump may begin as early as $24 \mathrm{~h}$, but when the injury is more severe may be delayed for weeks. Regeneration depends on activity at a specialized growth cone at the tip of each axonal sprout (Chierzi et al., 2005; Krystosek and Seeds, 1981). Calcium is important for growth cone formation (Dahlin, 2006). The receptivity of the injured tissue to accepting a regenerating axon is also a critical factor. Schwann cells contacted by a regenerating sprouts redifferentiate, begin to express normal myelin mRNAs and begin the process of ensheathing and remyelinating the fresh axon. The growth cone produces a protease that helps dissolve material blocking its path. With severe injuries that disrupt the endoneurial tubes, regenerating sprouts may encounter formidable obstacles. A critical factor is the length of the gap between the proximal and distal stumps. Axons that cannot reach the distal stump are wasted; they may wander into adjacent tissue or become encased in the scar that invariably forms within the gap between the proximal and distal stumps. Scar within the bridging tissue impedes regeneration and leads to misdirection and aberrant regeneration, as axons sprout into functionally unrelated endoneurial tubes.

Axonal regeneration is a tenuous and delicate process with intricate maneuvering of the advancing sprout orchestrated by signal transduction (Gallo and Letourneau, 2002; Kuffler, 1994; Zheng and Kuffler, 2000). The process leading to growth cone formation begins within hours after injury, and many sprouts arise from each parent axon. Growth cones send out finger-like extensions, filopodia, that explore and sample the environment, acting as long distance sensors (Dahlin, 2006; Kater and Rehder, 1995). Growth cones have remarkable abilities to detect navigational cues. Proper reading and integration of these cues is essential for precise rewiring of the regenerating nerve. The mobility of the growth cones at the ends of axon sprouts depends on receptors on the growth cones that receive guidance cues from the local environment. These navigation signals control growth cone advance, turning, and branching. Growth cones appear to be guided by at least four different mechanisms: contact-mediated attraction, chemoattraction, contact-mediated repulsion, and chemorepulsion. These mechanisms are mediated by many different families of guidance molecules (Goodman, 1996). These mechanisms seem to act simultaneously and in a coordinated manner to direct pathfinding (Tessier-Lavigne and Goodman, 1996). The growth cone's actin filaments are common targets for this guidance signaling. Navigational cues trigger local accumulation of actin filaments that promote lengthening of filopodia. Guidance cues have been classified as either attractive or repulsive (Mueller, 1999). Growth cones in vivo simultaneously encounter positive and negative guidance cues; and growth cone behavior during axonal pathfinding reflects the complex integration of multiple signaling activities (Gallo and Letourneau, 2004; Kolodkin, 1996). The response of growth cones to axon guidance molecules is dynamic and can be rapidly and differentially modulated by neurotrophins acting at the growth cone via tyrosine kinase receptors. Collapsin-1 is an inhibitory axon guidance molecule that can lead to growth cone collapse. The activity of neurotrophins, particularly BDNF, can lessen the susceptibility of the growth cone to the effects of collapsin-1 (Tuttle and O'Leary, 1998). Different treatments have explored improving nerve regeneration post-operatively, including drugs (such as FK506), hyperbaric oxygen, hormones, exercise, ultrasound and low level laser therapy (Anders et al., 2004; Gigo-Benato et al., 2005; Gordon et al., 2003; Gudemez et al., 2002; Mourad et al., 2001; Sarikcioglu and Oguz, 2001; Udina et al., 2002; Weber and Mackinnon, 2005).

Axons that successfully enter the endoneurial tubes in the distal stump stand a good chance of reaching the end 
organ. The growth cone contains multiple filopodia that adhere to the basal lamina of the Schwann cell and use it as a guide. Reported rates of axon regeneration range from 0.5 to $9 \mathrm{~mm} /$ day in different species and using different techniques. Clinically, an estimate of $1 \mathrm{~mm} /$ day or $1 \mathrm{in./}$ month is generally used. The variability depends on several factors. Regeneration is better proximally and in younger individuals (Burnett and Zager, 2004). Regeneration after surgical repair is slower than spontaneous regeneration. Axon regeneration is not synonymous with return of function. Even after the axon reaches its target, a maturation process must evolve, including remyelination, axonal enlargement, and the establishment of connections with the end organ before functional recovery can ensue.

Although nerve regeneration has been improved by several interventions in small animal models, no therapy addressing the molecular mechanisms of nerve regeneration in humans is yet available (Hoke, 2006). No method has been developed to ameliorate many of the critical problems, such as slow regeneration of axons across the injury site or the progressive loss of the ability to support regeneration in the distal portion of the nerve, which is likely due largely to Schwann cell atrophy and loss of Schwann cell tubes. There is current research aimed at improving the ability of neurons to regenerate, increasing the speed of axonal sprouting, and preventing loss of basal lamina (Fenrich and Gordon, 2004; Gordon et al., 2003).

Incomplete motor recovery after moderate to severe injuries may be due to a number of factors. Muscle fibers atrophy quite rapidly (Burnett and Zager, 2004). Fibrotic changes can be detected in the muscle as early as 3 weeks postinjury (Kline, 2008a). If the muscle is not reinnervated, fibrosis gradually progresses and will replace the muscle completely within about 2 years (Guttmann and Young, 1944). Reinnervation must occur within approximately 12-18 months to provide a functional outcome. Even when there is successful reinnervation, the muscle seldom returns to normal strength (Sunderland, 1978). Intramuscular fibrosis may limit contractile efficiency and aberrant regeneration may reduce the synergy of contraction (Sumner, 1990). Axonal misdirection, or pathfinding errors, is particularly problematic with proximal injuries to large mixed nerves.

\section{Nerve injury classification schemes}

As discussed above, Seddon classified nerve injuries as neurapraxia, axonotmesis and neurotmesis. Sunderland recognized five degrees of nerve injury (Table 1). Sunderland's first, second and fifth degree lesions correspond to Seddon's classification of neurapraxia, axonotmesis and neurotmesis. The Sunderland classification adds two useful subclasses of axonotmesis. In a third degree lesion there is axonotmesis, with not only axonal but endoneurial discontinuity, while the perineurium is preserved (Fig. 1). The endoneurial disruption inhibits regeneration. The scaffolding created normally by the Schwann cell tubes is distorted, and the environment is less receptive to regenerating axons, which tends to decrease successful regeneration. There is variable reinnervation, less efficient than with a second degree lesion, rarely to more than $60-80 \%$ of normal function. In a fourth degree lesion the internal structure is completely disrupted, only the epineurium is intact and nerve continuity is maintained purely by scar tissue. The nerve is grossly intact but the internal scarring blocks regenerating axons from reaching the distal stump. The severe internal disruption precludes effective reinnervation, and regenerating sprouts create a ball or mass of nerve fibers (neuroma in continuity). The fifth degree lesion is a nerve not in continuity. No reinnervation occurs in fourth and fifth degree lesions without surgical repair. To paraphrase Sunderland, the five degrees of injury are (1) neurapraxia, (2) loss of continuity of the axons without breaching the endoneurial sheath of the nerve fibers, (3) loss of continuity of nerve fibers, (4) involvement of the perineurium and the fasciculi, and (5) loss of continuity of the nerve trunk (Sunderland, 1978). There has been some drift from Sunderland's original definitions of his degrees of injury, enough to cause occasional confusion, especially among nonsurgeons. For instance, one authoritative source defines the degrees of injury thusly, "Grade II is a pure axonotmetic injury...Grade III is a more severe lesion which usually has a mixture of axonotmetic and neurotmetic axons. Grade IV is a neurotmetic lesion in continuity in which endoneurial and perineurial connective tissue layers as well as axons are disrupted. Grade $\mathrm{V}$ is a transecting injury with...interruption of all connective tissue layers" (Kline, 2008a).

A simpler classification scheme has been proposed that divides nerve injuries into either nondegenerative or degenerative (Thomas and Holdorff, 1993). Nondegenerative injuries produce no axon loss. Degenerative lesions are separated into those with preservation of endoneurial tubes, injuries with partial section of the nerve, and injuries with complete transection of the nerve. This classification scheme was prompted by the fact that the Seddon and Sunderland classifications are often misunderstood and misused (Birch, 2005). However, it is difficult to see how it adds much to the debate or to the clinical care of patients.

With brachial plexus injuries it is important to determine whether there has been avulsion of one or more roots from the spinal cord. This is important because such injuries do not recover and performing plexus surgery distal to a root avulsion is pointless (Terzis and Kostopoulos, 2007; Bertelli and Ghizoni, 2006; Belzberg, 2005). The presence or absence of a sensory nerve action potential is critical in this determination clinically. With root avulsions, the lesion is proximal to the dorsal root ganglion; the nerve cell body is intact and the sensory potential is preserved in the face of dense sensory loss and severe weakness. If the lesion involves the plexus, the sensory potential disappears because the peripheral process is disconnected from the cell body. With T1 root avulsion, a Horner syndrome is often present. CT myelography or MRI demonstrating the pres- 

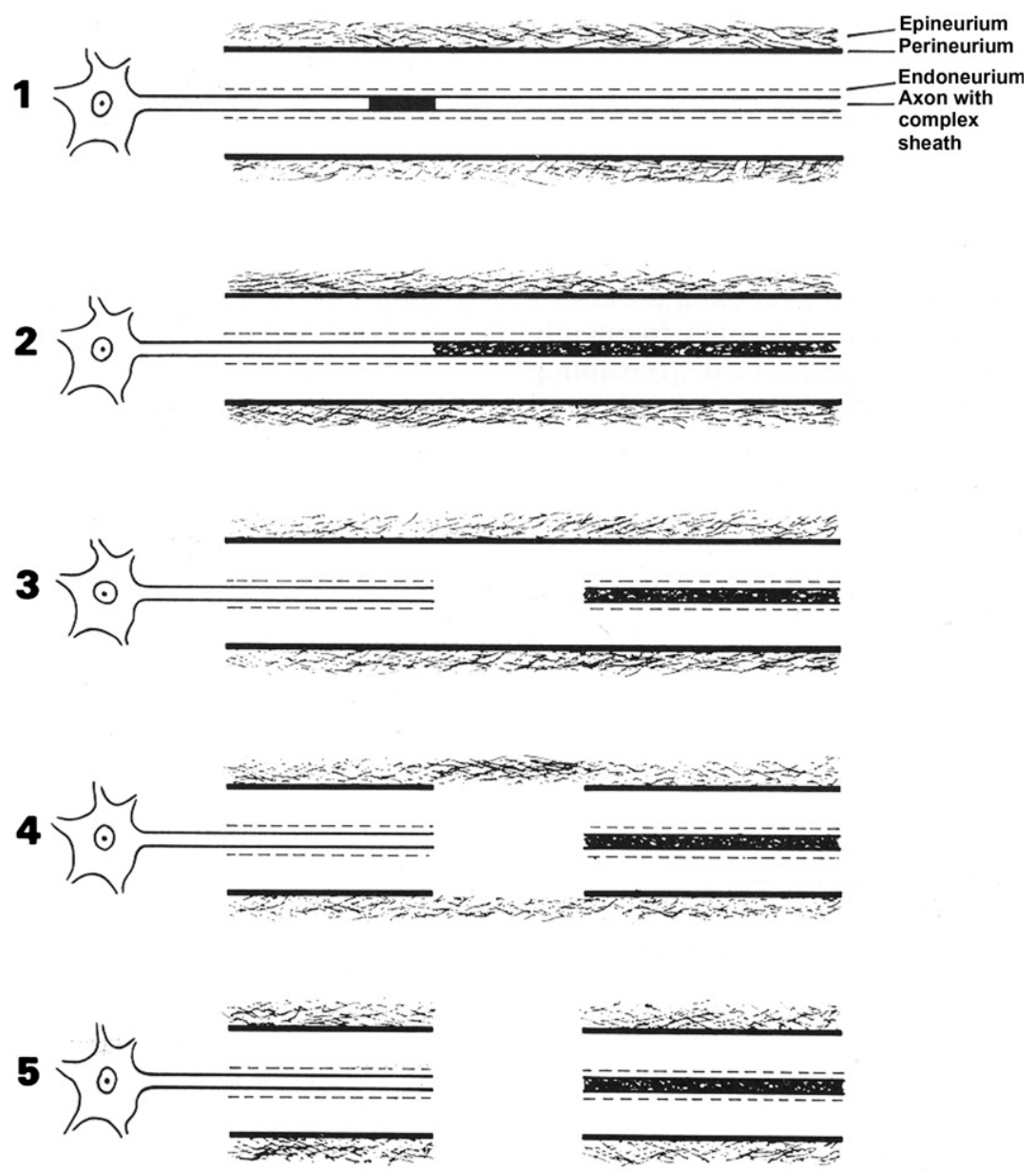

Fig. 1. Diagrammatic representation of the five degrees of nerve injury. (1) Segmental demyelination causing conduction block but no damage to the axon and no Wallerian degeneration, (2) damage to the axon severe enough to cause Wallerian degeneration and denervation of the target organ, but with an intact endoneurium and good prospects for axon regeneration, (3) disruption of the axon and its endoneurial sheath inside an intact perineurium, loss of integrity of the endoneurial tubes will limit axon regeneration, (4) disruption of the fasciculi, with nerve trunk continuity maintained only by epineurial tissue, severe limitation of axon regeneration, formation of a mass of misdirected axons (neuroma in continuity), (5) transaction of the entire nerve trunk. (Modified from Sunderland S. Nerves and nerve injuries, 2nd ed. Baltimore: ***Williams and Wilkins, 1978.)

ence of pseudomeningoceles is further evidence favoring root avulsion. These entities often do not occur in pure form, as the forces required to avulse a root also often severely injure the plexus, abolishing the sensory potential. So the absence of a sensory potential does not alone prove the absence of a root avulsion.

Physical examination, including eliciting Tinel sign, is useful in following patients with peripheral nerve injury. A flicker of movement or some degree of preserved sensation indicates that the lesion is incomplete. Substitute or "trick" movements often make the determination challenging. A trick movement is when the patient uses a normal muscle or movement to substitute for a weak muscle. For instance, the "bartender's sign" is when a patient with weak elbow flexion pulls the elbow backwards when the examiner tries to examine the biceps (Campbell, 2005). With a first degree lesion, the Tinel sign remains focal over the area of abnormality, and, although there may be weakness, muscle atrophy, except for that due to disuse, does not develop because there is no axon loss. With a second degree lesion, neurogenic atrophy does develop, sometimes rapidly, and the Tinel sign moves distally at approximately $1 \mathrm{in./month}$, indicating advancement of the axonal growth cone. With a third degree lesion, there is atrophy, and the Tinel sign does progress distally, but at a slower than expected rate. With fourth degree and fifth degree lesions, atrophy is usually severe and rapid, but the Tinel sign never migrates distally. Mixed lesions are relatively common, with some degree of neurapraxia accompanied by variable degrees of axonal damage. Some sources refer to mixed lesions as a Sunderland sixth degree lesion, although Sunderland did not include such a category. With clinically and electrophysiologically complete lesions, the return of function as gauged by a flicker of movement on physical examination or the return of motor unit action potentials (MUAPs) by EMG examination indicates that reinnervation is occurring. The EMG is more sensitive than the physical examination for detecting early reinnervation, so return of MUAPs on needle examination in the muscle closest to the injury site is typically the first evidence of 
reinnervation. Evidence of reinnervation can be detected by EMG weeks to months before voluntary contraction is visible (Kline, 2008b). The first evidence of reinnervation is usually the appearance of a low amplitude, highly polyphasic, fast firing, "nascent" MUAP.

\section{Surgical considerations}

In the early management of peripheral nerve injury, control of pain is the most pressing consideration. The pain is typically neuropathic, characterized by burning and dysesthesias, and requires medications which are specific for neuropathic pain, such as tricyclic antidepressants, serotonin reuptake inhibitors, anti-convulsants such as carbamazepine, phenytoin, and lamotrigine, gabapentin and pregabalin, antiarrhythymics, baclofen and others (Dworkin et al., 2003; Kingery, 1997). The mechanism of action of these drugs is thought to be the reduction of neuronal hyperexcitability, peripherally or centrally. Although traditional analgesics are not regarded as first-line drugs for treating neuropathic pain, agents such as nonsteroidal anti-inflammatory drugs, tramadol, and opioids may be useful. When used to treat neuropathic pain, opioid analgesia is dose-dependent and related to serum levels (Kingery, 1997). Topical agents such as lidocaine patches and capsaicin may be useful. Transcutaneous electrical nerve stimulation may be useful in some instances. When these measures fail, the pain may be controlled with a peripheral nerve block or with an indwelling catheter. It is important to maintain passive joint range of motion. Sensorimotor reeducation may play an important role. Desensitization techniques may help reduce pain and allodynia. Static or dynamic splinting may both help protect the injured part and improve function. There is experimental evidence in rats that electrical stimulation of denervated muscle helps preserve bulk and contractile responses (Cole and Gardiner, 1984; Herbison et al., 1983). Other experimental stimulation studies have not shown any improvement of mass or force (Dow et al., 2006). In humans with spinal cord injury, studies using spiral CT have shown promising results from electrical stimulation of denervated muscle (Helgason et al., 2005). There has been a paucity of electrical stimulation studies on humans with peripheral nerve injury (Eberstein and Eberstein, 1996). Boonstra et al. were unable to demonstrate any beneficial effect of low frequency electrical stimulation on denervation atrophy in man (Boonstra et al., 1987). Studies comparing the ability of electrical stimulation to promote functional recovery after peripheral nerve injury between rats and humans have shown some promising results in patients with carpal tunnel syndrome (Gordon et al., 2007). Overall, there is very little supportive data in humans to support the widespread use of electrical stimulation of denervated muscles. The patient must become actively involved in the treatment program, and this may require psychological evaluation and counseling.

Surgical repair of peripheral nerve trauma is done at varying time intervals after the injury, depending on the specific circumstances (Siemionow and Sari, 2004; Spinner and Kline, 2000). Nerve transections or lacerations may be sharp or blunt. Sharp transections produce relatively little trauma to the nerve stumps. Immediate reconstruction, within $72 \mathrm{~h}$, is often done for sharp transections, e.g., glass or knife wounds, when there has been complete nerve section, the nerve ends are healthy (not contused), and there has been minimal local tissue trauma. The best results with nerve repair occur with primary end-to-end neurorrhaphy. Anastomosis is not the proper term to use for nerve repair because it refers to the joining of hollow structures. If the nerve is not repaired acutely, there is retraction of the proximal and distal stumps, increasing the gap and increasing the likelihood that grafting will be needed to bridge the gap, lessening the likelihood of a good outcome. Results with grafting are not as good as with end-to-end repair. Other indications for acute nerve surgery include compression by a hematoma or pseudoaneurysm. Early reconstruction, after several weeks, is done for blunt transection or avulsion, sharp laceration where immediate surgery was not done, and complete lesions where the need for surgery is already certain, for example when nerve discontinuity was noted during surgery for vascular repair. Blunt transection usually occurs from the application of a large degree of force from a semi-sharp object, such as a propeller blade. After several weeks the degree of damage to the proximal and distal stumps can be better assessed. Blunt transactions encountered acutely are best managed by tacking down the stumps in anticipation of later end-toend repair. Delayed reconstruction, the most common approach, is done when nerve continuity is uncertain or when natural recovery could be better than surgery. One of the major precepts of peripheral nerve surgery is that incomplete lesions do better without surgery. A common approach where nerve continuity is uncertain, or there has been blunt or massive trauma, is to wait to see if there is clinical or EMG evidence of reinnervation, then to operate on those without evidence of reinnervation. Intervention is usually done by 6 months, often as early as 3 months with proximal injuries.

There are a number of considerations in deciding when to operate. There are three critical temporal factors. Resolution of segmental demyelination requires $8-12$ weeks, so deficits that persist beyond that period of time indicate that there has been axonal damage (Mackinnon and Dellon, 1988; Rudge et al., 1974). Under ideal conditions axon regrowth from the proximal stump occurs at $1 \mathrm{~mm}$ /day. The time after which irreversible muscle atrophy has occurred and operation cannot provide benefit is 12-18 months. The Schwann cells and the endoneurial tubes remain viable for 18-24 months after injury. If they do not receive a regenerating axon within this span of time, the tubes degenerate. Reinnervation must occur not only before the muscle undergoes irreversible changes, but before the endoneurial tubes will no longer support nerve regrowth. The time distance equation thus has two primary variables: irreversible changes in critical target structures 
after $12-18$ months, and axon regrowth at $1 \mathrm{~mm} /$ day from the site of injury or the site of surgical repair. Good outcome is considered return of function to MRC grade 3/5 (muscle can move against gravity but not resistance). Another major precept of peripheral nerve surgery is "when you have nothing, a little means a lot".

The primary surgical techniques used include external neurolysis, end-to-end repair, nerve grafting and nerve transfer (Spinner and Kline, 2000). There are very few controlled studies that have looked carefully at the outcomes with different types of peripheral nerve surgical techniques. External neurolysis is done to decompress a partially injured nerve by removing or incising the external epineurium. For complete lesions, primary end-to-end repair is preferable when possible and has the best prognosis (Diao and Vannuyen, 2000). The goals of surgery are to join healthy nerve to healthy nerve and to align the fascicles. The injured portion of the nerve is shaved back in each direction until a normal, healthy fascicular pattern is visible, then neurorrhaphy is performed using surface landmarks and other indicators to align the fascicles. If the gap between the proximal and distal stumps cannot be made up in order to do a tension-free end-to-end neurorrhaphy, grafting or transfer is used. Whether to graft or perform neurorrhaphy is determined by the width of the gap and the status of the nerve stumps. When a graft is used, a portion of the regenerating axons is lost across each suture line. Hence the preference for direct repair when the gap can be made up and a tension-free neurorrhaphy performed. Tension at the repair site will cause scarring that blocks the advance of regenerating sprouts. When grafting is necessary the graft may sometimes be constructed of a synthetic conduit or nonneural tissue. More often a noncritical nerve, generally the sural, is used to bridge the gap. A graft is preferable to an end-to-end repair under tension. Nerve transfers employ other intact motor nerves that have a minor function to reinnervate critical muscles. The distal end of a freshly cut normal nerve is joined to the distal stump of an injured nerve. A variation is to join selected fascicles from a normal nerve to an injured nerve. For instance, fascicles of the ulnar nerve may be implanted into the musculocutaneous nerve or biceps muscle in order to gain elbow flexion (Oberlin procedure) (Noaman et al., 2004). Other commonly used nerve transfers include using the distal spinal accessory nerve or an intercostal nerve to reinnervate the musculocutaneous. End-to-side repair is a recently developed technique in which the end of a healthy donor nerve is attached to the side of a target nerve distal to the site of injury (Matsuyama et al., 2000; Papalia et al., 2007a,b; Rowan et al., 2000). In lieu of grafting, other types of nerve substitute, such as vein grafts, synthetic nerve conduits, Schwann cell-lined nerve conduits, and nerve transplants are areas of current investigation and limited clinical use (Mackinnon et al., 2001; Weber and Mackinnon, 2005). The use of fibrin based tissue glue for coapting nerves is gaining popularity, especially when the need for a strong repair site is lessened because the repair does not span a joint. Various experimental strategies have been tried to promote functional recovery after peripheral nerve injuries (Gordon et al., 2003).

\section{Electrophysiology}

Both nerve conduction studies and needle electromyography contribute significant information in the evaluation and management of TPNI (Aminoff, 2004; Chaudhry et al., 1992; Robinson, 2000). In neurapraxia, the compound muscle action potential (CMAP) and nerve action potential (NAP) elicited on stimulation distal to the lesion are maintained indefinitely. Stimulation proximal to the lesion reveals partial or complete conduction block, with varying degrees of loss of CMAP amplitude, change in CMAP configuration and slowing of conduction velocity, depending on the attributes of a particular lesion. These abnormalities should improve or disappear when remyelination is complete, provided there is no persistent pressure on the nerve. Some conduction slowing may persist permanently because remyelination characteristically leaves shorter, thinner internodes than were present originally, but this does not interfere with function. Late responses (F-waves and $\mathrm{H}$-waves) are occasionally useful with extremely proximal lesions where it is not possible to directly stimulate proximal to the lesion, otherwise they are seldom of significant help.

In a complete neurapractic lesion, needle EMG will show no MUAPs under voluntary control, but fibrillations are not present. Some investigators have suggested that fibrillations can occur in purely neurapractic lesions, but spontaneous activity in this situation is more likely to indicate a mixed lesion with minimal axon loss, since needle EMG is sensitive for detecting minor degrees of axon loss. The predominant abnormality on needle EMG in partial neurapraxia is abnormal recruitment. Since some axons are blocked and the available motor units are decreased in number, the unaffected motor units must fire more rapidly than normal to generate force. The typical finding is a decreased number of MUAPs of normal amplitude, duration and configuration, which fire rapidly. Because there is no axon loss, and because resolution occurs relatively rapidly, there is no remodeling of the motor unit in neurapraxia.

The electrodiagnostic picture in axonotmesis and neurotmesis depends on the time that has passed between the injury and the evaluation. The CMAP and NAP distal to the injury decrease in amplitude in rough proportion to the degree of axon loss. This loss of amplitude is complete by day 9 for CMAPs and day 11 for NAPs. The earlier loss of the CMAP is related to changes in the neuromuscular junction. With any degree of injury, a study carried out in the first few days may show no conduction abnormality except for inability to conduct an impulse across the lesion on proximal stimulation. A conduction study done at any time after the injury will show no significant conduction 
changes distal to the lesion if the lesion is neurapractic. If there has been significant axon loss, there will be progressive loss of muscle and nerve action potentials in the distal stump, such that a study carried out 10-14 days after an electrophysiologically complete lesion will demonstrate an inexcitable nerve. After the first 1-2 weeks, when Wallerian degeneration distal to the lesion is complete and conduction in the affected axons is lost, the degree of axon loss vs. segmental demyelination can be judged by the ratio of the CMAP amplitude on the injured side to the normal side (estimate of axon loss) and the distal amplitude compared to the proximal amplitude (demyelination). For example, if an examination 1 month after injury reveals a CMAP amplitude on distal stimulation about half of that on the contralateral side, about $50 \%$ of the axons have been lost. If on stimulation proximal to the lesion, the CMAP amplitude drops by another $50 \%$, then about half of the surviving axons have also suffered conduction block. This is at best an approximation, since the CMAP amplitudes obtained from homologous muscles on the two sides are seldom the same.

Needle EMG findings can indicate axon loss, but do not quantify the degree of loss, except to distinguish between electrophysiologically complete and incomplete lesions. Abundant fibrillation potentials may be seen even when axon loss is only moderate. If the lesion is electrophysiologically complete there will be no motor units under voluntary control in muscles innervated by the injured nerve, and the nerve will be inexcitable distal to the injury. The appearance of fibrillations and positive sharp waves is time and length-dependent; they do not appear for a number of days after the injury. In proximal muscles they appear after 10-14 days and in distal muscles after 3-4 weeks. When using needle EMG, beware of possible confounding abnormalities due to direct muscle trauma (Partanen and Danner, 1982). In lesions with partial axon loss, the motor unit abnormalities shortly after the injury are the same as in neurapraxia, i.e., a decreased number of normal appearing MUAPs that fire rapidly. As collateral sprouting occurs, remodeling of the motor units begins. Single fiber EMG (SFEMG) studies have demonstrated evidence of reinnervation as early as 3 weeks after injury (Massey and Sanders, 1991). As remodeling continues, the surviving MUAPs develop complexity, with an increased number of turns, evolving into polyphasia. Fully reinnervated MUAPs are large amplitude, long duration and polyphasic, all reflecting an increased motor unit territory. With a complete lesion, the first MUAPs to appear with reinnervation are typically highly polyphasic, small, and fire extremely rapidly (nascent units). Such units can be recorded from a muscle that has no clinically visible movement. With recovering complete lesions, once MUAPs begin to appear they rapidly increase in number, often going from a few units to a handful to an abundance over a period of several weeks. Early in reinnervation the MUAPs are very unstable, with a great deal of jittering, jiggling and blocking that can be seen with routine needle examination.
The MUAP instability occurs because the new axon sprouts are incompletely myelinated and have immature neuromuscular junctions that frequently fail. The jittering and blocking can be better demonstrated by SFEMG. Another phenomenon that can be seen with SFEMG is neurogenic blocking, in which several fibers block as a group because an immature axonal sprout at a branch point leading to several muscle fibers has failed to conduct. As sprouts and neuromuscular junctions mature and become more stable, the jitter, jiggling and blocking resolve, leaving a complex, polyphasic but stable MUAP that indicates that the reinnervation mechanisms have progressed as far as they are capable of, and reinnervation is as complete as it is going to get. Disappearance of MUAP instability in a muscle that has not regained satisfactory strength could be construed as an indication for surgical exploration.

Although conventional teaching usually holds that an electrodiagnostic study should not be done until about 3 weeks after the injury, a great deal of important information can be obtained by studies done in the first week. Some textbooks state that an EMG performed within days of nerve injury, even a severe injury, will be normal (Belzberg, 2005). This reflects serious misunderstandings and misconceptions about the neurophysiology of nerve injury. While there may be no spontaneous or increased insertional activity on an early EMG, the study will be far from normal. The period of time when the distal stump continues to conduct allows for precise localization of the injury, since there will be no conduction across the site of any major injury associated with anatomical disruption but preserved conduction in the distal stump. Detection of such axon discontinuity conduction block precisely identifies the site of the responsible lesion. This is particularly useful where there has been extensive trauma and the nerve could have been damaged at any location within a relatively large area. This localization opportunity is lost when the distal stump ceases to conduct after about 1 week. Another advantage of an early study is to determine whether the lesion is electrophysiologically complete or incomplete, which determines prognosis and the likely necessity for surgical intervention. With incomplete lesions there are MUAPs under voluntary control in the involved muscles. The number of MUAPs is inversely proportional to the severity of the injury. But even a single MUAP indicates that the lesion is electrophysiologically incomplete and that the nerve trunk is not completely disrupted. Incomplete lesions have a better prognosis and there is much less likelihood that surgery will be necessary. After the first 1-2 weeks, the electrodiagnostic study can still determine whether the neurological deficit is due to neurapraxia (distal stump continues to conduct) or a more severe anatomical disruption with axonotmesis or neurotmesis (distal stump no longer conducts). A study done at 3-4 weeks, after fibrillation potentials have had a chance to develop, provides the greatest amount of information at a single sit- 
ting. A study done at 3 or 4 months may detect early reinnervation.

In these patients, it is sometimes difficult to be certain which muscle the needle is in, especially in the face of distorted anatomy due to massive trauma, crush injuries, fasciotomy and the like. It may be critically important to distinguish one particular muscle from adjacent muscles, e.g., the median innervated flexor digitorum superficialis from the anterior interosseous innervated lateral head of the flexor digitorum profundus. A useful technique in these circumstances is direct needle stimulation of the muscle. With a monopolar needle electrode and a surface anode, using nerve conduction technique and low intensity stimulation (e.g., $0.1 \mathrm{~ms}$ duration and $10-20 \mathrm{~mA}$ current), the needle is advanced until a twitch is visible that indicates stimulation of the target muscle, e.g., twitch at the distal interphalangeal joint rather than the proximal interphalangeal joint (it is not necessary to record). Without moving the needle, the wires are reattached to the recording inputs and the needle examination is conducted as usual.

Based on these considerations the optimal timing for an electrodiagnostic study depends upon the clinical question being asked: (1) immediate to 7 days for localization; telling complete from incomplete, (2) 1-2 weeks for telling complete vs. incomplete; sorting axonotmesis or neurotmesis from neurapraxia, (3) 3-4 weeks for the most diagnostic information from a single study, and (4) 3-4 months for detecting reinnervation.

\section{EMG in surgical planning: when to explore}

Electrodiagnostic studies are useful in planning the timing of surgical exploration. The calculation must assume a Sunderland fourth or fifth degree injury that will require either direct repair or grafting. A measurement is made from the injury site to the most critical muscle to reinnervate, and assumes that, if surgery is necessary, sprouts from the repair site must reach that muscle before irreversible changes occur in the muscle in 12-18 months. At $1 \mathrm{in} . / \mathrm{month}$, calculate the time required for sprouts from the injury site to reach the first target muscle in line for reinnervation. If the first target muscle does not reinnervate on time, explore. Some additional time, usually several weeks, is added for the possibility of a Sunderland third degree lesion, where reinnervating sprouts will arrive, just not in the expected time. For example, assume an electrophysiologically complete median lesion in the mid-forearm, 8 in. proximal to the thenar muscle group. If surgery must be done, the procedure must be timed so that the thenar muscles are reinnervated by about one year after injury. Surgery done at 4 months postinjury would suffice, leaving 8 months for reinnervating fibers from the repair site to reach the muscle. The first target muscle in line for reinnervation in this scenario would be the flexor pollicis longus. If there is no evidence of reinnervation of the flexor pollicis longus by 4 months postinjury, the nerve should be explored.

Proximal nerve injuries, above the elbow and above the knee, are problematic because the long distance sprouts must travel making it difficult to reinnervate critical distal muscles before irreversible changes occur. Clinical decision making regarding exploration must occur over a much shorter time frame. An alternative approach is to explore using intraoperative nerve action potential (NAP) recording to guide the choice of surgical procedure (Brown and Veitch, 1994; Crum and Strommen, 2007; Holland, 2002; Kline and DeJonge, 1968; Kline and Happel, 1993; Slimp, 2000; Spinner and Kline, 2000). If a NAP can be recorded across the lesion, then external neurolysis is performed. If no NAP can be recorded, end-to-end repair or graft is the preferable procedure. During split or partial repair, it may be necessary to record NAPs from specific fascicles (Williams and Terzis, 1976). If a tourniquet is used to achieve a bloodless field, it must be deflated for at least 30 min before attempting to record NAPs.

\section{Outcomes of surgery for traumatic nerve injury}

There are several recognized factors that influence the outcome after repair of a TPNI (Belzberg, 2005). Two major factors favoring a good functional outcome are youth and distal injury, both because of the shorter distance and the more discrete separation of motor and sensory fascicles that can be matched in the proximal and distal stumps. Better functional recovery occurs with endto-end repair than with grafting. Operations done early have a better outcome than those done later, and an unfortunate number of patients are "observed" until the time for optimal surgical intervention by an expert peripheral nerve surgeon is long past. Lack of subspecialty training in peripheral nerve surgery and an inexperienced surgeon are clear impediments to a satisfactory outcome. Although muscles are irreversibly damaged after about 18 months, the sensory fibers and sensory receptors survive for a much longer period, and surgery done much later, even years later, may restore protective sensation to an insensate part. Procedures such as tendon transfers and vascularized free muscle transfer, the gracilis is frequently used, can restore function even when the prime mover of a part is irreversibly denervated.

In 1998, Kline et al. reported a retrospective clinical study of a 24-year experience with the management and results of sciatic nerve injuries in 380 patients (Kline et al., 1998). In $60 \%$, the injury was at the buttock level, and injection injuries made up more than half of these cases. Thigh-level injury occurred in $40 \%$ and was usually secondary to gunshot wound, femoral fracture, laceration, or contusion. Patients with partial deficits uncomplicated by severe pain or with significant spontaneous recovery or late referral were managed medically. Surgical exploration was not indicated in $23 \%$ of injuries at the thigh level and almost $50 \%$ of those at the buttock level. Most of these 
patients achieved partial but good spontaneous recovery, especially in the tibial division distribution. Surgical intervention was done for complete deficits in $77 \%$ of the thigh level cases and $50 \%$ of the buttock cases. Whether to perform neurolysis or resection was guided by NAP recordings. Significant recovery was obtained in only $36 \%$ of patients who had suture or graft repairs of the peroneal division. Good-to-excellent outcome was common for the tibial division, even when repair was proximal and required lengthy grafts. The relatively favorable recovery of tibial as opposed to peroneal divisions of the sciatic nerve occurred regardless of the level or mechanism of injury. Taha and Taha reported the outcome of 27 patients who had the sciatic nerve sutured above the knee 3-14 weeks after missile injury (Taha and Taha, 1998). In adults, recovery was significantly better after suture of tibial $(83 \%)$ than peroneal $(39 \%)$ nerves, after thigh $(71 \%)$ than buttock $(31 \%)$ level injuries, and after end-to-end neurorrhaphy (74\%) than grafting $(39 \%)$. Roganovic et al. reported a prospective study of 119 patients with missile-induced complete lesions of the tibial nerve or tibial division (Roganovic et al., 2005). There was a successful outcome in $30.3 \%$ of highlevel, $50 \%$ of intermediate-level, and $85.7 \%$ of low-level repairs $(p<0.001)$. On average, the length of the gap and the preoperative interval were significantly shorter in patients with a good outcome. A worse outcome occurred with a nerve defect longer than $5 \mathrm{~cm}$ and a preoperative interval longer than 4 months.

Useful recovery of sensory and motor functions was studied prospectively after 393 graft repairs of the median, ulnar, radial, tibial, peroneal, femoral, and musculocutaneous nerves (Roganovic and Pavlicevic, 2006). Sensory recovery potential was similar for all nerves tested $(p>0.05)$, but motor recovery potential differed significantly. After high-level repairs, useful motor recovery was better for the radial $(66.7 \%)$ and tibial $(54.5 \%)$ nerves than for the ulnar $(15.4 \%)$ and peroneal $(13.8 \%)$ nerves $(p<0.05)$. After intermediate-level repairs, motor recovery was better for the musculocutaneous $(100 \%)$, radial $(98.3 \%)$, and femoral nerves $(87.5 \%)$, than for the tibial $(63.9 \%)$, median $(52 \%)$ and ulnar $(43.6 \%)$ nerves $(p<0.05)$. Motor recovery was significantly worse with peroneal nerve repairs $(15.2 \%)(p<0.05)$. After low-level repairs, motor recovery potential was similar for all nerves with useful recovery in the range of $88.9-100 \%$ except for peroneal nerve repairs $(56.3 \%)$.

Kretschmer et al. studied iatrogenic nerve injuries in 722 surgically treated nerve injuries. They found that $17.4 \%$ of the 722 cases were iatrogenic, most from a previous operation. Many of the patients with iatrogenic lesions were not seen within a time frame conducive to surgical management; of those who did have surgery, some improvement occurred in $70 \%$. One of the major causes of poor outcome in patients with iatrogenic lesions is delayed referral to a surgeon with peripheral nerve expertise (Kretschmer et al., 2001). There are many studies examining outcomes in carpal tunnel syndrome using different surgical tech- niques (Thoma et al., 2004). There are also outcomes data available in regard to a number of specific nerves, including the posterior interosseous (Kim et al., 2006a), the anterior interosseous (Kim et al., 2006b), median (Kim et al., 2001a), ulnar (Kim et al., 2003a; Secer et al., 2007), radial (Kim et al., 2001b), and axillary (Kline and Kim, 2003). Kim et al. studied the outcomes of 1019 surgically managed brachial plexus lesions. Repairs had the best outcome with injuries located at the C-5, C-6, and C-7 levels, the upper and middle trunk, the lateral cord to the musculocutaneous nerve, and the medial and posterior cords to the axillary and radial nerves. Results were poor with C-8 and T-1 injuries and for lower trunk and medial cord lesions. Careful selection of cases, especially considering such factors as lesion type, location, severity, and time since injury were associated with better outcomes (Kim et al., 2003b).

\section{References}

Ahlborn P, Schachner M, Irintchev A. One hour electrical stimulation accelerates functional recovery after femoral nerve repair. Exp Neurol 2007;208:137-44.

Al Majed AA, Tam SL, Gordon T. Electrical stimulation accelerates and enhances expression of regeneration-associated genes in regenerating rat femoral motoneurons. Cell Mol Neurobiol 2004;24:379-402.

Aminoff MJ. Electrophysiologic testing for the diagnosis of peripheral nerve injuries. Anesthesiology 2004;100:1298-303.

Anders JJ, Geuna S, Rochkind S. Phototherapy promotes regeneration and functional recovery of injured peripheral nerve. Neurol Res 2004;26:233-9.

Belzberg AJ. Acute nerve injuries. In: Rengachary SS, Ellenbogen RG, editors. Principles of neurosurgery. 2nd ed. Edinburg: Elsevier Mosby; 2005. p. 387-95.

Bertelli JA, Ghizoni MF. Use of clinical signs and computed tomography myelography findings in detecting and excluding nerve root avulsion in complete brachial plexus palsy. J Neurosurg 2006;105:835-42.

Birch R. Operating on peripheral nerves. In: Dyck PJ, Thomas PK, editors. Peripheral neuropathy. 4th ed. Philadelphia: Elsevier Saunders; 2005. p. 1511-32.

Boonstra AM, van Weerden TW, Eisma WH, Pahlplatz VB, Oosterhuis HJ. The effect of low-frequency electrical stimulation on denervation atrophy in man. Scand J Rehabil Med 1987;19:127-34.

Brown WF, Veitch J. AAEM minimonograph \#42: intraoperative monitoring of peripheral and cranial nerves. Muscle Nerve 1994;17:371-7.

Burnett MG, Zager EL. Pathophysiology of peripheral nerve injury: a brief review. Neurosurg Focus 2004;16:1-7.

Campbell WW. DeJong's the neurologic examination. 6th ed. Philadelphia: Lippincott, Williams and Wilkins; 2005.

Chaudhry V, Glass JD, Griffin JW. Wallerian degeneration in peripheral nerve disease. Neurol Clin 1992;10:613-27.

Chierzi S, Ratto GM, Verma P, Fawcett JW. The ability of axons to regenerate their growth cones depends on axonal type and age, and is regulated by calcium, cAMP and ERK. Eur J Neurosci 2005;21:2051-62.

Cole BG, Gardiner PF. Does electrical stimulation of denervated muscle, continued after reinnervation, influence recovery of contractile function?. Exp Neurol 1984;85:52-62.

Costigan M, Mannion RJ, Kendall G, Lewis SE, Campagna JA, Coggeshall RE, et al. Heat shock protein 27: developmental regulation and expression after peripheral nerve injury. $\mathbf{J}$ Neurosci 1998;18:5891-900.

Creange A, Barlovatz-Meimon G, Gherardi RK. Cytokines and peripheral nerve disorders. Eur Cytokine Netw 1997;8:145-51. 
Crum BA, Strommen JA. Peripheral nerve stimulation and monitoring during operative procedures. Muscle Nerve 2007;35:159-70.

Dahlin LB. Nerve injury and repair: from molecule to man. In: Slutsky DJ, Hentz VR, editors. Peripheral nerve surgery: practical applications in the upper extremity. Philadelphia: Churchill Livingstone, Elsevier; 2006. p. 1-22.

Davis JB, Stroobant P. Platelet-derived growth factors and fibroblast growth factors are mitogens for rat Schwann cells. J Cell Biol 1990;110:1353-60.

Diao E, Vannuyen T. Techniques for primary nerve repair. Hand Clin 2000;16:53-66, viii.

Dow DE, Carlson BM, Hassett CA, Dennis RG, Faulkner JA. Electrical stimulation of denervated muscles of rats maintains mass and force, but not recovery following grafting. Restor Neurol Neurosci 2006;24:41-54.

Dumitru D, Zwarts MJ, Amato AA. Peripheral nervous system's reaction to injury. In: Dumitru D, Amato AA, Zwarts M, editors. Electrodiagnostic medicine. 2nd ed. Philadelphia: Hanley and Belfus; 2001. p. 115-56.

Dworkin RH, Backonja M, Rowbotham MC, Allen RR, Argoff CR, Bennett GJ, et al. Advances in neuropathic pain: diagnosis, mechanisms, and treatment recommendations. Arch Neurol 2003;60:1524-34.

Eberstein A, Eberstein S. Electrical stimulation of denervated muscle: is it worthwhile? Med Sci Sports Exerc 1996;28:1463-9.

Fenrich K, Gordon T. Canadian association of neuroscience review: axonal regeneration in the peripheral and central nervous systemscurrent issues and advances. Can J Neurol Sci 2004;31:142-56.

Fu SY, Gordon T. The cellular and molecular basis of peripheral nerve regeneration. Mol Neurobiol 1997;14:67-116.

Funakoshi H, Frisen J, Barbany G, Timmusk T, Zachrisson O, Verge VM, et al. Differential expression of mRNAs for neurotrophins and their receptors after axotomy of the sciatic nerve. J Cell Biol 1993; 123:455-65.

Gallo G, Letourneau P. Axon guidance: proteins turnover in turning growth cones. Curr Biol 2002;12:R560-2.

Gallo G, Letourneau PC. Regulation of growth cone actin filaments by guidance cues. J Neurobiol 2004;58:92-102.

Geremia NM, Gordon T, Brushart TM, Al Majed AA, Verge VM. Electrical stimulation promotes sensory neuron regeneration and growth-associated gene expression. Exp Neurol 2007;205:347-59.

Gigo-Benato D, Geuna S, Rochkind S. Phototherapy for enhancing peripheral nerve repair: a review of the literature. Muscle Nerve 2005;31:694-701.

Goodman CS. Mechanisms and molecules that control growth cone guidance. Annu Rev Neurosci 1996;19:341-77.

Gordon T, Sulaiman O, Boyd JG. Experimental strategies to promote functional recovery after peripheral nerve injuries. J Peripher Nerv Syst 2003;8:236-50.

Gordon T, Brushart TM, Amirjani N, Chan KM. The potential of electrical stimulation to promote functional recovery after peripheral nerve injury-comparisons between rats and humans. Acta Neurochir Suppl 2007;100:3-11.

Gudemez E, Ozer K, Cunningham B, Siemionow K, Browne E, Siemionow M. Dehydroepiandrosterone as an enhancer of functional recovery following crush injury to rat sciatic nerve. Microsurgery 2002;22:234-41.

Guttmann E, Young JZ. Reinnervation of muscle after various periods of atrophy. J Anat 1944;78:15-43.

Hall SM. Regeneration in the peripheral nervous system. Neuropathol Appl Neurobiol 1989;15:513-29.

Hall SM. The biology of chronically denervated Schwann cells. Ann N Y Acad Sci 1999;883:215-33.

Hall S. Mechanisms of repair after traumatic injury. In: Dyck PJ, Thomas PK, editors. Peripheral neuropathy. Philadelphia: Elsevier, Saunders; 2005. p. 1403-33.

Hartmann JE. Neurology in operation iraqi freedom: risk factors for referral, clinical presentations and incidence of disease. J Neurol Sci 2006;241:83-90.
Helgason T, Gargiulo P, Johannesdottir F, et al. Monitoring muscle growth and tissue changes induced by electrical stimulation of denervated degenerated muscles with $\mathrm{CT}$ and stereolithographic 3D modeling. Artif Organs 2005;29:440-3.

Herbison GJ, Jaweed MM, Ditunno Jr JF. Acetylcholine sensitivity and fibrillation potentials in electrically stimulated crush-denervated rat skeletal muscle. Arch Phys Med Rehabil 1983;64:217-20.

Hirasawa Y, Sakakida K. Sports and peripheral nerve injury. Am J Sports Med 1983;11:420-6.

Hoke A. Mechanisms of disease: what factors limit the success of peripheral nerve regeneration in humans? Nat Clin Pract Neurol 2006;2:448-54.

Holland NR. Intraoperative electromyography. J Clin Neurophysiol 2002;19:444-53.

Ito $\mathrm{Y}$, Yamamoto $\mathrm{M}$, Li M, Doyu M, Tanaka F, Mutch $\mathrm{T}$, et al. Differential temporal expression of mRNAs for ciliary neurotrophic factor (CNTF), leukemia inhibitory factor (LIF), interleukin-6 (IL-6), and their receptors (CNTFR alpha, LIFR beta, IL-6R alpha and gp130) in injured peripheral nerves. Brain Res 1998;793:321-7.

Kang H, Tian L, Thompson W. Terminal Schwann cells guide the reinnervation of muscle after nerve injury. J Neurocytol 2003;32:975-85.

Kater SB, Rehder V. The sensory-motor role of growth cone filopodia. Curr Opin Neurobiol 1995;5:68-74.

Kim DH, Kam AC, Chandika P, Tiel RL, Kline DG. Surgical management and outcomes in patients with median nerve lesions. J Neurosurg 2001a;95:584-94.

Kim DH, Kam AC, Chandika P, Tiel RL, Kline DG. Surgical management and outcome in patients with radial nerve lesions. J Neurosurg 2001b;95:573-83.

Kim DH, Han K, Tiel RL, Murovic JA, Kline DG. Surgical outcomes of 654 ulnar nerve lesions. J Neurosurg 2003a;98:993-1004.

Kim DH, Cho YJ, Tiel RL, Kline DG. Outcomes of surgery in 1019 brachial plexus lesions treated at Louisiana State University Health Sciences Center. J Neurosurg 2003b;98:1005-16.

Kim DH, Murovic JA, Kim YY, Kline DG. Surgical treatment and outcomes in 45 cases of posterior interosseous nerve entrapments and injuries. J Neurosurg 2006a;104:766-77.

Kim DH, Murovic JA, Kim YY, Kline DG. Surgical treatment and outcomes in 15 patients with anterior interosseous nerve entrapments and injuries. J Neurosurg 2006b;104:757-65.

Kingery WS. A critical review of controlled clinical trials for peripheral neuropathic pain and complex regional pain syndromes. Pain 1997;73:123-39.

Kline DG. Selected basic considerations. In: Kim DH, Midha R, Murovic JA, Spinner RJ, editors. Kline \& Hudson's nerve injuries. 2nd ed. Philadelphia: Elsevier Saunders; 2008a. p. 1-21.

Kline DG. Clinical and electrical evaluation. In: Kim DH, Midha R, Murovic JA, Spinner RJ, editors. Kline \& Hudson's nerve injuries. 2nd ed. Philadelphia: Elsevier, Saunders; 2008b. p. 43-63.

Kline DG, DeJonge BR. Evoked potentials to evaluate peripheral nerve injuries. Surg Gynecol Obstet 1968;127:1239-48.

Kline DG, Happel LT. Penfield lecture. A quarter century's experience with intraoperative nerve action potential recording. Can J Neurol Sci 1993;20:3-10.

Kline DG, Kim DH. Axillary nerve repair in 99 patients with 101 stretch injuries. J Neurosurg 2003;99:630-6.

Kline DG, Kim D, Midha R, Harsh C, Tiel R. Management and results of sciatic nerve injuries: a 24-year experience. J Neurosurg 1998;89:13-23.

Koeppen $\mathrm{AH}$. Wallerian degeneration: history and clinical significance. J Neurol Sci 2004;220:115-7.

Koliatsos VE, Price WL, Pardo CA, Price DL. Ventral root avulsion: an experimental model of death of adult motor neurons. J Comp Neurol 1994;342:35-44.

Kolodkin AL. Growth cones and the cues that repel them. Trends Neurosci 1996;19:507-13.

Kouyoumdjian JA. Peripheral nerve injuries: a retrospective survey of 456 cases. Muscle Nerve 2006;34:785-8. 
Kretschmer T, Antoniadis G, Braun V, Rath SA, Richter HP. Evaluation of iatrogenic lesions in 722 surgically treated cases of peripheral nerve trauma. J Neurosurg 2001;94:905-12.

Krystosek A, Seeds NW. Plasminogen activator release at the neuronal growth cone. Science 1981;213:1532-4.

Kuffler DP. Promoting and directing axon outgrowth. Mol Neurobiol 1994;9:233-43.

Lewis SE, Mannion RJ, White FA, Coggeshall RE, Beggs S, Costigan M, et al. A role for HSP27 in sensory neuron survival. J Neurosci 1999;19:8945-53.

Li L, Houenou LJ, Wu W, Lei M, Prevette DM, Oppenheim RW. Characterization of spinal motoneuron degeneration following different types of peripheral nerve injury in neonatal and adult mice. J Comp Neurol 1998;396:158-68.

Liuzzi FJ, Tedeschi B. Peripheral nerve regeneration. Neurosurg Clin N Am 1991;2:31-42.

Lunn ER, Brown MC, Perry VH. The pattern of axonal degeneration in the peripheral nervous system varies with different types of lesion. Neuroscience 1990;35:157-65.

Mackinnon SE, Dellon AL. Surgery of the peripheral nerve. New York: Thieme; 1988.

Mackinnon SE, Doolabh VB, Novak CB, Trulock EP. Clinical outcome following nerve allograft transplantation. Plast Reconstr Surg 2001;107:1419-29.

Maggi SP, Lowe III JB, Mackinnon SE. Pathophysiology of nerve injury. Clin Plast Surg 2003;30:109-26.

Maricevic A, Erceg M. War injuries to the extremities. Mil Med 1997;162:808-11.

Martini R. Expression and functional roles of neural cell surface molecules and extracellular matrix components during development and regeneration of peripheral nerves. J Neurocytol 1994;23:1-28.

Massey JM, Sanders DB. Single-fiber EMG demonstrates reinnervation dynamics after nerve injury. Neurology 1991;41:1150-1.

Matsuyama T, Mackay M, Midha R. Peripheral nerve repair and grafting techniques: a review. Neurol Med Chir (Tokyo) 2000;40:187-99.

Mourad PD, Lazar DA, Curra FP, Mohr BC, Andrus KC, Avellino AM, et al. Ultrasound accelerates functional recovery after peripheral nerve damage. Neurosurgery 2001;48:1136-40.

Mueller BK. Growth cone guidance: first steps towards a deeper understanding. Annu Rev Neurosci 1999;22:351-88.

Murphy PG, Borthwick LS, Johnston RS, Kuchel G, Richardson PM. Nature of the retrograde signal from injured nerves that induces interleukin-6 mRNA in neurons. J Neurosci 1999; 19:3791-800.

Nicholson DW, Thornberry NA. Caspases: killer proteases. Trends Biochem Sci 1997;22:299-306.

Noaman HH, Shiha AE, Bahm J. Oberlin's ulnar nerve transfer to the biceps motor nerve in obstetric brachial plexus palsy: indications, and good and bad results. Microsurgery 2004;24:182-7.

Papalia I, Cardaci A, d'Alcontres FS, Lee JM, Tos P, Geuna S. Selection of the donor nerve for end-to-side neurorrhaphy. J Neurosurg 2007a;107:378-82.

Papalia I, Geuna S, d'Alcontres FS, Tos P. Origin and history of end-toside neurorrhaphy. Microsurgery 2007b;27:56-61.

Partanen JV, Danner R. Fibrillation potentials after muscle injury in humans. Muscle Nerve 1982;5:S70-3.

Pollock M. Nerve regeneration. Curr Opin Neurol 1995;8:354-8.

Raff MC, Whitmore AV, Finn JT. Axonal self-destruction and neurodegeneration. Science 2002;296:868-71.

Richardson PM, Lu X. Inflammation and axonal regeneration. J Neurol 1994;242:S57-60.

Robinson LR. Traumatic injury to peripheral nerves. Muscle Nerve 2000;23:863-73.

Robinson LR. Traumatic injury to peripheral nerves. Suppl Clin Neurophysiol 2004;57:173-86.

Roganovic Z, Pavlicevic G. Difference in recovery potential of peripheral nerves after graft repairs. Neurosurgery 2006;59:621-33.
Roganovic Z, Pavlicevic G, Petkovic S. Missile-induced complete lesions of the tibial nerve and tibial division of the sciatic nerve: results of 119 repairs. J Neurosurg 2005;103:622-9.

Rowan PR, Chen LE, Urbaniak JR. End-to-side nerve repair. A review. Hand Clin 2000;16:151-9, x.

Rudge P, Ochoa J, Gilliatt RW. Acute peripheral nerve compression in the baboon. J Neurol Sci 1974;23:403-20.

Rydevik B, Lundborg G. Permeability of intraneural microvessels and perineurium following acute, graded experimental nerve compression. Scand J Plast Reconstr Surg 1977;11:179-87.

Sarikcioglu L, Oguz N. Exercise training and axonal regeneration after sciatic nerve injury. Int J Neurosci 2001;109:173-7.

Secer HI, Daneyemez M, Gonul E, Izci Y. Surgical repair of ulnar nerve lesions caused by gunshot and shrapnel: results in 407 lesions. J Neurosurg 2007;107:776-83.

Seckel BR. Enhancement of peripheral nerve regeneration. Muscle Nerve 1990;13:785-800.

Seddon H. Three types of nerve injury. Brain 1943;66:237-88.

Selecki BR, Ring IT, Simpson DA, Vanderfield GK, Sewell MF. Trauma to the central and peripheral nervous systems. Part I: an overview of mortality, morbidity and costs; N.S.W. 1977. Aust N Z J Surg 1982;52:93-102.

Siemionow M, Sari A. A contemporary overview of peripheral nerve research from the Cleveland Clinic microsurgery laboratory. Neurol Res 2004;26:218-25.

Slimp JC. Intraoperative monitoring of nerve repairs. Hand Clin 2000;16:25-36.

Spinner RJ, Kline DG. Surgery for peripheral nerve and brachial plexus injuries or other nerve lesions. Muscle Nerve 2000;23:680-95.

Stanec S, Tonkovic I, Stanec Z, Tonkovic D, Dzepina I. Treatment of upper limb nerve war injuries associated with vascular trauma. Injury 1997;28:463-8.

Stoll G, Muller HW. Nerve injury, axonal degeneration and neural regeneration: basic insights. Brain Pathol 1999;9:313-25.

Sulaiman OA, Gordon T. Effects of short- and long-term Schwann cell denervation on peripheral nerve regeneration, myelination, and size. Glia 2000;32:234-46.

Sumner AJ. Aberrant reinnervation. Muscle Nerve 1990;13:801-3.

Sunderland S. Nerves and nerve injuries. 2nd ed. Baltimore: Williams and Wilkins; 1978.

Sunderland S. The anatomy and physiology of nerve injury. Muscle Nerve 1990;13:771-84.

Taha A, Taha J. Results of suture of the sciatic nerve after missile injury. J Trauma 1998;45:340-4.

Tanabe K, Bonilla I, Winkles JA, Strittmatter SM. Fibroblast growth factor-inducible-14 is induced in axotomized neurons and promotes neurite outgrowth. J Neurosci 2003;23:9675-86.

Taniuchi M, Clark HB, Johnson Jr EM. Induction of nerve growth factor receptor in Schwann cells after axotomy. Proc Natl Acad Sci USA 1986;83:4094-8.

Terzis JK, Kostopoulos VK. The surgical treatment of brachial plexus injuries in adults. Plast Reconstr Surg 2007;119:e73-92.

Tessier-Lavigne M, Goodman CS. The molecular biology of axon guidance. Science 1996;274:1123-33.

Thoma A, Veltri K, Haines T, Duku E. A meta-analysis of randomized controlled trials comparing endoscopic and open carpal tunnel decompression. Plast Reconstr Surg 2004;114:1137-46.

Thomas PK. Invited review: focal nerve injury: guidance factors during axonal regeneration. Muscle Nerve 1989;12:796-802.

Thomas PK, Holdorff B. Neuropathy due to physical agents. In: Dyck PJ, Thomas PK, Griffin JW, editors. Peripheral neuropathy. 3rd ed. Philadelphia: W.B. Saunders; 1993. p. 990.

Tuttle R, O'Leary DD. Neurotrophins rapidly modulate growth cone response to the axon guidance molecule, collapsin-1. Mol Cell Neurosci 1998;11:1-8.

Udina E, Ceballos D, Verdu E, Gold BG, Navarro X. Bimodal dosedependence of FK506 on the rate of axonal regeneration in mouse peripheral nerve. Muscle Nerve 2002;26:348-55. 
Weber RV, Mackinnon SE. Bridging the neural gap. Clin Plast Surg 2005;32:605-16.

Wilbourn AJ. Peripheral neuropathies associated with vascular diseases and the vasculitides. In: Brown WF, Bolton CF, Aminoff MJ, editors. Neuromuscular function and disease. Philadelphia: Saunders; 2002. p. 1229-62.

Williams HB, Terzis JK. Single fascicular recordings: an intraoperative diagnostic tool for the management of peripheral nerve lesions. Plast Reconstr Surg 1976;57:562-9.

Yawo H, Kuno M. Calcium dependence of membrane sealing at the cut end of the cockroach giant axon. J Neurosci 1985;5:1626-32.
Ygge J. Neuronal loss in lumbar dorsal root ganglia after proximal compared to distal sciatic nerve resection: a quantitative study in the rat. Brain Res 1989;478:193-5.

Zheng M, Kuffler DP. Guidance of regenerating motor axons in vivo by gradients of diffusible peripheral nerve-derived factors. J Neurobiol 2000;42:212-9.

Zhivotovsky B. Caspases: the enzymes of death. Essays Biochem 2003;39:25-40.

Zochodne DW, Levy D. Nitric oxide in damage, disease and repair of the peripheral nervous system. Cell Mol Biol (Noisy-le-grand) 2005;51:255-67. 